\title{
Facts and Fiction in Positivism and Neo Positivism
}

\author{
Ayeni, Evans Oluwagbamila \\ Federal University Wukari, Wukari, Taraba State, Nigeria \\ Saman, Udi Polycarp \\ Federal University Wukari, Wukari, Taraba State, Nigeria \\ Sani Kasimu \\ Federal University Wukari, Wukari, Taraba State, Nigeria
}

\begin{abstract}
Facts and fiction are two sides of a coin; this is so because the former is backed up with evidence while the latter is imaginary in nature. Positivism is a method of gaining knowledge that is empirically based, while nonpositivism is also a method of gaining knowledge through secondary data and observation. Positivism is a method of gaining knowledge that originated from pure sciences, though its use has been accepted in the behavioural sciences. The study examines; facts and fiction in positivism and neo-positivism. The research method adopted for this study is the secondary sources or documentary research method found under qualitative research method. The method of research analysis used for this research is the 'Content Analysis Method'. The findings of this study are; Qualitative and quantitative research uses observation as the mode of gaining knowledge (use of our five senses); hence the two paradigms believe that anything that cannot be observed lacks validity. Quantitative and qualitative research aimed at the same goal, which is to build theory, prediction, generalization, and to gain knowledge. Even though quantitative and qualitative researches are facts based, they end up being infiltrated with imagination they initially try as much as possible to avoid. For instance, both research undertakings often than not fall victim of 'fallacy of band wagon', a situation where majority of the subjects (that questionnaire were administered to or subject that interview were administered to) give false observation about social phenomenon they have observed.
\end{abstract}

Keywords: Facts, fiction, positivism, neo-positivism, qualitative, quantitative

DOI: $10.7176 /$ RHSS/9-4-03

\section{Introduction}

In carrying out a good research, there is need for some elements of facts and not fiction. There are two major ways of carrying out facts based research in behavioural sciences, which are positivism and neo-positivism (nonpositivism or post-positivism). In fact, Obiora and Udalla (2018:29-31) observes that, "a paradigm is an integrated set of assumptions, beliefs, models of doing good research, and techniques for gathering and analyzing data. There are two major popular paradigms in the contemporary social science: positivism and postpositivism. From observation, research is said to be a positivist inclined when such research follows some scientific ways of carrying out research by going to the field and after that subject the study hypotheses, to some mathematical analysis or using other scientific method of analysis. On the other hand, non-positivism is a system of enquiry or method of carrying out research that try to explain social phenomenon with the aid of research questions, without necessarily testing hypotheses. In the course of carrying out research, it is necessary to note that it is not every research that should follow a particular direction for facts to be obtained. Some research work might require participant observation while other might not require it.

Research in behavioural sciences and social sciences have come to term with positivism and neo-positivism or post-positivism depending on the nature of research that is under consideration. Marsonet (2002) observes that, "Positivism" was first coined by Saint Simon and was later popularized in the first half of the 19th Century by the French sociologist and philosopher, Auguste Comte (1798-1857) who is considered to be the father of the positivist movement. Positivism is a concept that was theorized by August Comte in the author's quest to find answers to technological development question that the idealism could not find answer to. Justifying the above is Padmanabhan and Gafoor, when they opine that:

Positivism was founded by Auguste Comte, who introduced the term "positivism". The neo-positivism is taken by the philosophical problems of language, symbolic logic, the structure of scientific investigations, and others. Having renounced psychologism, the exponents of the third positivism took the course of reconciling the logic of science with mathematics, the course of formalisation of epistemological problems (Padmanabhan \& Gafoor, 2011:19-20).

Positivism is believed to be capable of transforming society on the basis of science. This neo-positivism 
promotes qualitative research method. In the words of Peter (2018:81), "qualitative technique involves the collection of extensive narrative data on many variables over an extended period of time in a naturalistic setting. It uses participant observation in generating non-numerical data". Qualitative technique has the capacity of generating data that explains detail description because of participant observation it employed, when compared to quantitative technique that uses mostly structured questionnaire.

Research that is positivism inclined is usually backed up with facts or evidences which will eventually be tested through hypotheses that have been carefully prepared in form of assumptions. However, a hypothesis has the tendency of been a mere imagination, if the hypothesis end up being false after the outcome of the study or after hypotheses must have been tested by the researcher. On the other hand neo-positivism is also usually backed up with facts and evidences which will eventually be confirm through observation and review of action research. A research question in neo-positivism research can also be mere imagination if the research question end up being false after the outcome of the study and after going to the field, to observe and content analyzing the literature.

However, the reason for variations in the methods of carrying out research is on the premise of mere imagination by researchers that research must be based on quantification or measurement, while other researchers believe on the contrary. In fact, Alessandrini, (n.d: 4) contends that, "while a positivist perspective requires that objectivity is achieved by the suppression of the researcher's values so that just facts are deduced, a non-positivist would maintain that this is at best an arrogant claim". The observation that, it is only research that is positivism oriented that can achieve objective can also be an imagination, this is because the mere selection of research topic that deals with a particular phenomenon and not another is already value laden. Qualitative research has the tendency of being objective as well as quantitative research. This is because, both positivism (quantitative research) and neo-positivism (qualitative research) required the researcher to interpret results of findings; this itself can be subject to the researcher interpretation. Hence, the view that positivism is superior to neo-positivism is being fair. It is in line with this observation that Alessandrini opines that:

A positivist perspective is based on assumptions that the scientist; or social scientist in this case, is capable of suppressing his or her own views, values and experiences so effectively that objectivity can be achieved. A nonpositivist researcher exposes their subjectivity, disclosing as much as possible any biases or aspects of their biography that could be regarded as influencing the research proposal, data collection or analysis. This way, the reader is informed and able to compensate for this. There is no presumption that the researcher has some superior capacity to manage their own bias (Alessandrini, n.d: 4).

The fact that positivism believes in value free assumption to achieve objectivity, while the neo-positivism exposes their subjectivity by disclosing any likely bias that can influence research is itself objectivity. For the mere fact that neo-positivism discloses their bias beforehand is itself a move towards objectivity. In both positivism and neo-positivism, researchers have a greater role in interpreting mathematical data gotten from quantitative research as well as interpreting social phenomenon gathered from participant observation, interview and documentary sources in qualitative research.

However, it should be noted that positivism is not the earliest method of gaining knowledge; knowledge has been gained before the emergence of positivism. However, the emergence of positivism is in response to the shortcomings of idealism that was not able to meet the aspiration of thinkers in the earlier stage of knowledge acquisition. According to Padmanabhan and Gafoor:

A trend in bourgeois philosophy which declares natural (empirical) sciences to be the sole source of true knowledge and rejects the cognitive value of philosophical study. Positivism emerged in response to the inability of speculative philosophy (e.g. Classical German Idealism) to solve philosophical problems which had arisen as a result of scientific development. Positivists went to an opposite extreme and rejected theoretical speculation as a means of obtaining knowledge. Positivism declared false and senseless all problems, concepts and propositions of traditional philosophy on being, substances, causes, etc., that could not be solved or verified by experience due to a high degree of abstract nature. Positivism claims to be a fundamentally new, non-metaphysical ("positive") philosophy, modelled on empirical sciences and providing them with a methodology (Padmanabhan \& Gafoor, 2011:19).

Positivism is a child of necessity that came about when speculative philosopher (idealism) failed to solve philosophical problems that arose as a result of scientific development. The concept is believed to be rooted on empirical sciences with lay down procedures in knowledge acquisition. Supporting the forgoing is Pickering, M 
(1993:661), "supremacy of metaphysics (idealism) was overturned thanks to Bacon and especially Descartes, whom Comte considered the superior thinker. It now ruled only morality, while positivism controlled natural philosophy". The view that positivism rules over natural and physical sciences is in line with Yacob-Haliso (2016:10) view, positivist research emanates from the naturalistic view of science and produces quantitative research while post-positivist research is a family of research including critical, interpretive and hermeneutic traditions that produce qualitative research".

On the other hand, neo-positivism is distinct from pure sciences (natural and physical science) because the object of study differs from the latter. In the word of Alessandrini:

A non-positivist approach is distinct from pure science in that it is centred on the humanistic view of the social sciences. From this perspective, research concerning human behaviour cannot be regarded in the same way as other scientific research: The social world is distinctive and separate from the world of nature. Rather than experiment to test theories, non-positivists take an interpretivist stance, maintaining that experimenting on human behaviour, particularly social situations is virtually impossible to replicate reliably (Alessandrini, n.d:4).

Neo-positivism which promotes qualitative research method is centred on human behaviour, hence it cannot be treated the same way with other scientific method which study the world of nature. Bennett (1996:123) argues that, "knowledge in the post-positivist belief system in which we now live, is not regarded as conclusive, verifiable, or external to the human psyche, but instead is assumed to be tentative, socially and individually constructed". The scholar went further to say that, knowledge is "a matter of human imagination brought to bear on those perceptions that humans are capable of having. Knowledge is the basis of meaning. Meaning is a human invention". It does mean that, there is an element of human imagination in neo-positivist or qualitative research, though such imaginations have the tendency of being proven after careful investigation in research.

From the above, the need to investigate whether imagination otherwise known as 'fiction' has the tendency of creeping into positivism (quantitative research) and neo-positivism (qualitative research) is very central to this paper. Also, the issue on whether 'facts' which is the hallmark of every research is sacrosanct in positivism and non-positivism informed this study.

The following are the objectives of this study: To investigate how facts are discovered in positivism and neo positivism; to examine the role of fiction in quantitative and qualitative research.

\section{Research Methodology}

The research method adopted for this piece is qualitative research method. The research method was adopted because of the belief that, it can gather relevant information from secondary sources that allow in-depth analysis for the study under consideration. The study uses documentary study as instrument for collecting data. The reason for the research instrument was because it is economical, time saving and allow for in-depth analysis of previous researches on the subject. The researchers' have published in some reputable journals in Nigeria and outside the country, apart from completing their first degrees long essay (project) and second degree dissertations at postgraduate level. There is no doubt that the researchers had gotten some experiences in research work.

Content analysis was employed to analyze the content of the secondary source of data that include books, journals, government publication and other online materials. The author content-analyzed research works on facts and fiction in positivism and neo-positivism from books, academic journals, chapter contributions, and online materials from Nineteen century till date.

This research work covers the happenings on facts in positivism and neo-positivism on one hand; and fiction in quantitative research and qualitative research on the other hand. The population of the study is all researchers who have published either quantitative or qualitative research work.

\section{Conceptual issues}

Facts

Just like every other concepts, there is no acceptable definition of the concept of facts. However, Igwe (2007:151'), sees facts as "the building block of knowledge with its own unique attribute which may either be logically established or empirically verified, independent of man's will, even as such will may unfortunately affect the interpretations given it". To see facts as the building block of knowledge is the absolute truth, but to say that facts may either be logically established or empirically verified, independent of man's will is in doubt. The scholar went further to say that, 'even as such 'will' may unfortunately affect the interpretation given it' is ambiguous. It is ambiguous because, 'facts that are independent of man's will' seem to contradict the preceding phrase which says that, 'even as such will, may unfortunately affect the interpretation given it'. It does mean that, fact to some extent is dependent on the interpretation of the researcher; hence humans will affect interpretation 
of research.

In the words of Asika (2012:5), "a fact is almost synonymous with reality or what exists". The scholar went further to observe that, "a fact is a truth that can be known only by observation and or experience". To say that a fact is what exists is itself a reality. Further observation by the scholar that, 'fact is a truth that can be known only by observation and or experience' is doubtful. This is because observation and experience might not always represent the reality on ground. For instance, some participant observation might not show the true picture, as the people under observation can change their behavior when they know that they are being studied. Hence, fact might be difficult to get from people.

\section{Fiction}

In the words of Hoover Public Library (2018), fiction refers to literature created from the imagination. From the above observation, the concept of fiction is something that lacks facts or evidence. Fiction is a literature that is not based on fact and figure. Thus, the above is supported by Cambridge University Press (2018), fiction is the type of book or story that is written about imaginary characters and events and not based on real people and facts. The University Press, went further to define 'fiction' as, a false report or statement that you pretend is true. The above explanation believes that fiction is any documentary source or event that is not based on real world situation.

\section{Positivism}

Positivism is an approach which applies scientific method of natural science to study human activity using objective enquiry and thereby presupposes the unity of the sciences (Hollis, 1994: 41; Delanty, 2005:10 as cited in Buddharaksa, 2010:1). The above view is supported by Pickering (1993:589), "positivism used the inverse method. It subordinated the conception of man to that of the external world, made the concept of "natural laws" of primary importance, and opened up the possibility of extending such laws to man and society". Positivism is a method of gaining knowledge from applied science that has come to bear on behavioural science to study human activities. However, the subject of study in behavioural science differs from that of natural science, hence there is doubt if same method can be applied to both field.

\section{Neo positivism}

In the words of Alessandrini (n.d:4), "non-positivist research methodologies emphasize diversity and focus on the experiences of the researched group or individual as they have experienced them, regarding this as the most important data source". The scholar holds that, neo-positivism is a method of gaining knowledge that emphasizes on the experience of the researched groups as they have experienced them. This definition is the same thing as views hold by qualitative research method. Related to the above definition is the view of Remenyi (2014) when the scholar captured what non-positivist means in this manner; the central premise of non-positivist research is that the researcher should be concerned to understand phenomenon in depth and that this understanding should result from attempting to find tentative answers to questions such as 'what?' 'why? and 'How?'. Phenomenological contends that such understanding can result from using methods other than measurements. Neo-positivism school promotes qualitative research method that uses method to gain knowledge rather than measurement as obtainable in quantitative research (positivism).

The next section investigates the two sub-objectives of the study. They are; to investigate how facts are discovered in positivism and neo-positivism, on one hand; and to examine the role of fiction in quantitative and qualitative research.

\section{To investigate how facts are discovered in positivism and neo-positivism}

The presence of facts in every research is germane if knowledge must be gained. Gaining knowledge in behavioural sciences takes two dimensions. The first dimension of gaining knowledge is research through positivism that promotes quantitative research method. The second dimension of gaining knowledge is research through neo-positivism that promotes qualitative research method. The above observation is best captured by, Alessandrini, when the scholar contends that:

A positivist researcher emphasises quantitative data, using qualitative material to illustrate a conclusion drawn from statistics of some kind, a neopositivist favours qualitative data such as that collected from focus groups or interviews or text sources such as transcripts, reports or qualitative surveys. Empirical data may also be considered but is not regarded as any more credible or persuasive than the direct disclosures of those researched. Alessandrini (n.d:4)

Both positivism and neo-positivism paradigms are different in the approaches by which knowledge can be gained. The differences in the two approaches might be as a result of the type of study to be embarked upon by 
the researcher. The above observation is best explained by Buddharaksa (2010:3) when the researcher opines that, "positivism is useful for the research that tend to find out the simple relationship between each unit of analysis, usually be an individual, without counting on the influence of social structure". The nature of research to be carried out influences the type of research methodology to be employed, thus a research that is interested in finding out relationship between two units of analysis will be best carried out with positivism or quantitative research method. On the other hand, Michael Quinn Patton and Michael Cochran (2002:4) best explain when to use qualitative methodologies in research. In the researchers' words, neo-positivism (qualitative research method) can be used to uncover, "People's experiences of health needs, health care, accessing care and keeping healthy. Understanding different perspectives, such as those of professionals and patients. How experiences, attitudes and life circumstances affect health needs and behaviours". From the above observation, it is crystal clear that some facts can be best discovered through positivist approach (quantitative research), while others can also be discovered by means of neo-positivism (qualitative research method). To believe that facts can only be discovered through positivism (quantitative research method) which believe in observation and measurement, might not be right. The foregoing question is best answered by Albert Einstein as cited in Michael Quinn Patton and Michael Cochran (2002:2), when the scientist contends that, "Not everything that can be counted counts and not everything that counts can be counted." It is not everything that can be measured in research that is factual.

Moreover, both positivism and neo-positivism have the tendency of being factual and none of them is superior to the other. In fact, Babbie (1998 and 2003) posit that, "the process of writing quantitative and qualitative research is almost the same. But what specifically differentiates the two designs is methodology" (cited in Mbacha, 2016: 56). It is important to know that both quantitative and qualitative researches are backed up with facts, though their method of analysis differs. However, quantitative research is mostly used along with qualitative research, even though qualitative research can solely be embarked upon without the support of the former. To prove that positivism utilized neo-positivism method in research, Bennett opines that:

Arithmetical facts may be taken at face value ( 7 children, ranging in age from 5-9, completed the task within 3 minutes,...), any construct of them any attempt to make meaning of them - requires us to recognize that meaning itself is a human construct, peculiar to and limited by the particular kind of mental/physical organism humans happen to be (Bennett, 1996:123).

Even positivism that claimed to be the only method of gaining knowledge through science tends to employ the constructivist approach used by qualitative research. Positivism or quantitative research method find itself trying to interpret arithmetic data gotten from field, this implies that meaning in positivism or quantitative research also is researcher's construct, peculiar to and limited to the researcher mental analytical skills. To conclude that, it is only neo-positivism (qualitative research method) that is subjective in nature, while positivism (quantitative research method) is objective in nature is not a fair judgment.

More so, the issue of objectivity as the positivist claimed is utopia. Bennett (1996:123) best captured this, when the author opines that, "Objective truth- truth having an identity independent of human constructs - is taking to be a comforting myth, useful for our narcissistic purpose". Objective truth is a comforting myth. In fact, Alessandrini (n.d: 3) argues that, "social actions do not exist in and of themselves, but are dependent on their recognition and interpretation by social actors. Consequently it is through this interpretation that meaning is established". Whether positivism that promotes quantitative or non-positivism that promotes qualitative research methods, interpretation of social phenomenon is dependent on the researcher, hence both have the capacity to be objective in their findings. What is important is to know the research method that can best suite a particular research to be embarked upon. In the season of empiricism, Trochim posits what to do in gaining knowledge that can stand the test of time:

The best way for us to improve the objectivity of what we do is to within the context of a broader contentious community of truth-seeker (including other scientists) criticize each other's work. The theories that survive such intense scrutiny are a bit like the species that survive in the evolutionary struggle, hence such idea have 'survival value' and that knowledge evolves through a process of variation, selection and retention (Trochim, 2006)

Objectivity in research can be strengthen when true researchers, including scientists who are truth seeker consciously meet on a regular bases to critically peruse researchers work for the sole purpose of advancing knowledge, instead of insisting that a research must be quantitatively based before it can be regarded as being scientific.

Quantitative and qualitative research uses observation in collecting data. According to Mbachu (2016:57), "the most appropriate instrument to use in data collection is questionnaire". The above research method is best captured in the words of Blank (1998), quantitative research methodology refers to the application of numbers and figures to the primary data we generate with a view to applying them and consequently drawing certain inferences from the phenomenon in which we are investigating" (cited in Mbacha, 2016:56). On the other hand, 
qualitative research uses interview, focus group discussion, observations and action research as instruments of gathering data (Peter, 2018). Thus, the two instruments of gathering data in both research methods are aimed at gathering facts. Quantitative researchers called their method that involves the uses of questionnaire 'survey research'. Obiora and Udalla argue that:

Survey research came to be seen as a formal research method in the 19301940s when a sociologist Paul Lazarsfeld used it to examine the effects of the radio on political opinion formation of the United States. Since after 1940s, survey research method has become a very popular method for quantitative research in social sciences. It is suitable for studying individuals or groups, or organisations as units of analysis. In the case of studying an organization or group, individuals representing the group can be selected as a sample (Obiora \& Udalla (2018:22-23).

Survey research method used by quantitative research method has its own merits and demerits, the merits aspect of it is that it is suitable for studying individuals or groups or organisations as a unit of analysis. On the other hand, participant observation is suitable for studying issues that need in-depth studies.

The aim of every researcher is to test and build theory that can be universally accepted. The foregoing is what researchers in both positivism and neo-positivism have always tried to achieve. This fact is ascertained by Peter when the researcher observed that:

Qualitative research prompts a critical evaluation of existing theory that is based on the detailed observation of mechanisms. The qualitative efforts can be seen as a form of theory testing because they involve assessments of the credibility of the assumptions and mechanism underlying theories (Peter, 2018:84-85)

Researchers who are comfortable with qualitative research method employed theory in their research, the reason is to enable them use the study to explain certain postulation that a particular theory holds. These researchers not only use theory to assess situation based on observation, they sometimes try to build theory that can be universally accepted. Thus, Peter posits that:

Qualitative methods are used to investigate cases that are theoretically anomalous just like researchers in the natural sciences often conduct in-depth case studies of anomalous in other to resolve paradoxes and advance theory. This attention to anomalies explain why qualitative research is often the source of new theories and why careful attention to case selection is crucial to it success (Peter, 2018:85).

Theories building is central to both quantitative and qualitative research, therefore both approach are scientific since they are both methods used by researchers to advance knowledge. Many political scientists like David Easton among others have come up with theories that have now been accepted to both qualitative and quantitative researchers.

The need for validity in research is very central in carrying out research work; this is so because of the need to ensure external validity that will help in the course of generalisation. There is need for external validity because the purpose of every research is to make prediction for generalization. The uses of certain words are employed by the positivism in the quest to ensure objectivity. This objectivity is not only applicable to positivism, but also neo-positivism. Bennett (1996:123), submit that, "in positivist mind-set, when using language we must push it as far as we can to the objective condition of mathematics, avoiding the sloppiness of subjectivity that can creep in if we are not careful, such as calling ourselves "I" rather than "the researcher," or calling the people we are researching "they" rather than "subjects," and so on. However, the mere use of language in research is not enough ground to determine whether a research will be objective or not, even though both positivism and neo-positivism employed try as much as possible to use objective language that positivism has claim credit on. Knowing fully well that the essence of research is to advance knowledge in the ways things are being done, Pickering (1993:618-619) holds that, "social dynamics was the source of the idea of progress, which, Comte believed, gave sociology its most distinctive character and went further to say that positivism would never be able to create the perfect society because the moral and mental weaknesses of man would never disappear".

In scientific research, knowledge is gained through five senses. In the words of Yacob-Haliso, experience is the basis for knowledge. Only knowledge apprehended by the use of five human senses can be considered to exist as such knowledge can also be experienced by others coming into contact with it, and does not depend on the say-so of any single person (Yacob-Haliso, 2016:8). Knowledge is what is gained through research, meaning that it has been there all this while waiting to be discovered. It is not what someone tells you that it is, but rather what everybody came to know as the truth.

There is also a school of thought that believed that any research that is not mathematical or quantifiable is 
not scientific. In fact, scholars like Azom (2018:331) has come down heavily on this notion, "the impression that measurement has to do with quantification or the assignment of numerals only is somewhat narrow because". It is not only by assigning numbers that qualifies a research to have measurement attribute of the positivist. McQueen \& Knussen (2002) argue that, "aspect of our universe can be measured in more than one way, with the choice of particular method a function both of the nature of what is being measured and the researcher's judgment and preference" (as cited in Biereenu-Nnabugwu, 2006:147). What can be deduced from the above is that, social phenomenon can be measured quantitatively and qualitatively. Putting the dichotomy of quantification and qualification at rest, Biereenu-Nnabugwu (2006) further holds that, measurement operates at the following five levels; text-coding verbal information into various categories, nominal-36 states in Nigeria, ordinal-academic performance ranked as $1^{\text {st }} 2^{\text {nd }}$ and $3^{\text {rd }}$ positions, interval and radio.

Qualitative research is facts based just as quantitative research is. Thus, for the fact that qualitative research involves the collection of extensive narrative through observation and not by wishful thinking is a research that is rooted on fact. The above is best explained by Peter (2018:83-84) when the scholar opines that, "qualitative technique involves the collection of extensive narrative data (non-numerical data) on many variables over an extended period of time, in order to gain insights into phenomena of interest". To say that qualitative research is not fact rooted is to say nothing as an intellectual. It should be noted that both qualitative and quantitative research are facts based research, hence both should be used according to the one that best suit the purpose of the research.

Quantitative and qualitative research as being science based research. Igwe (2007:134) best captured what empiricism is all about when the scholar posits that, "the quest for knowledge through observation or experience, the essence of positivism and the scientific method". The view of Obasi Igwe is related to that of Bodner (2018), empirical evidence is information that verifies the truth or falsity of a claim. The research went further to observe that, empirical evidence is information acquired by observation or experimentation. This data is record and analysed by scientists. From the above observation, it is crystal clear that knowledge that is scientific based must be gained only through observation which must be recorded and analysed. The requirement of recording and analyses of data gained through observation are features of both qualitative and quantitative research method. Whether research is positivism based (quantitative research) or neo-positivism based is not an issue, what is important here is that the purpose of social scientific research is to fulfill five purposes for it to qualify as a scientific research. Yacob-Haliso best captured this explanation:

The five purpose of conducting social scientific research are for: Exploration-is aimed at investigating a little known phenomenon in other to gather information about it. It is useful in opening up new ground; description-is aimed at answering what, how, where, when question in research, and the key scientific tool for this is observation; understanding-is when the relationship that exists among these facts is deduced in order to cast light on specific social processes; explanation - is aimed at answering the crucial "why" question which seeks to provide the set of observable phenomena that can be identifies from other phenomena being studied; and lastly prediction-is the explanation of future behaviour or events (YacobHaliso, 2016:8-9).

For research to claim 'scientific based', such must be able to take up the nature of scientific research, that is, it should be able to perform the function of exploration, description, understanding, explanation and prediction. From above observation, it is crystal clear that positivism (quantitative research) and neo-positivism (qualitative research) are facts based and should be used based of the nature of research to be embarked upon. In fact, Easton asserts that political science must be normatively relevant and empirically reliable" (Peter, 2018:94).

\section{To examine the role of fiction in quantitative and qualitative research}

The role of fiction in quantitative research (positivism) and qualitative research (neo-positivism) is most often denied by researchers. However there is doubt if fiction does not perform any role in behavioural sciences. In fact, Rogers best explains the roles fiction play in research that has to do with arts and humanities:

Historical novels teach many historical events to readers while the reader is empathetic to the characters and their situations in the novels. Even diaries and testimonials that contain narratives merge nonfiction and fiction. The element of fiction allows readers to connect with the reader and imagine living through the historical event. Ethnographers use natural settings to collect data and produce thick descriptions of specific cultures. While collecting the data, the researcher's subjective experience influences what is observed, recorded, and described in the final story (Rogers, 2014:2)

Research in humanities often at times employed fiction in writing; this is carried out in form of 
exaggeration of testimonies in narration which readers believe to be truth. This exaggeration by writers in the process of narration is often carried over to further research as truth for scholars who might consult such literature as secondary source. In the quest to understand the role of fiction in research, Rogers ask the following questions and provide answers to them:

How does a researcher write culture and share the writing with others? At what point is the story considered nonfiction or fiction? Fiction as a research practice helps answer these questions and provides researchers an outlet to share the story of culture with others. Creative nonfiction began in the 1960 's to help with engagement while remaining truthful in research reports. Researchers needed the use of literary tools to strengthen their factual writing. Creative nonfiction made nonfiction stories read like fiction to help with the connection of the reader to the true story and to affect the readers in a positive way. After examining the above genres, one can easily see the importance for researchers to have the ability to use fiction to represent their data and to connect with their readers (Rogers, 2014:2).

Researchers in humanities use creativity in writing to make their writing look real, especially in trying to communicate a particular way of life to the readers. For instance, some nations or tribes tend to narrate story of their existence by adding some imaginary picture just to drive home their point. For instance, the Yoruba's believed that Orunmila was sent to the world by God to help mankind. In fact Odu Ifa (n.d) holds that,

Orunmila was said to have lived in the spiritual realm for more than 400 years without food and water before descending to earth to help mankind. He set foot first on Oke-Igbeti and later to other part of Yoruba land where he lived for the betterment of mankind. He was the wisest human to have lived on earth with power of perfect foretelling and prediction together with his ability to read human thoughts (cited in Olalekan, 2015:1).

There is no doubt that some creative imagination must have been added to the story of how Orunmila came into this world by the Yoruba. The observation that a mere mortal have once lived in the spiritual realm is an imagination. This story shows how most tribes in Nigeria add creative imagination to the story of their leaders at one point or the other. Thus, such stories have come to be believed by people to the extent that researchers use this information in further research, either in qualitative or quantitative research. When story of creative imagination is being asked from the people in the course of interview or administering of questionnaire, most people are bound to answer 'yes' because that is what they have come to agree as a people of such tribe. How story of one's culture and the other is being passed is often times the work of creative imagination to make story look real to the reader. Although creative nonfiction is educative, it has element of imagination that are not real. In fact, Rogers (2014:2) argued that, "fiction-based research is a specific type of arts-based research and is assessed by its own measures with more emphasis on writing practices. This is done by having detailed descriptions of the people and places in the story that feel authentic to the readers". Rogers believes that creative imagination research which is known as fiction based research is a type of research that is carried out in arts. This goes to show that, creative imagination has become a research tool in art, though not in social and management sciences. From the above observation, creative imagination is seen as a research instrument in arts based research. The role of fiction in arts based research cannot be overestimated; this is because we live in an imaginary world. However, the world of imagination cannot be equated to the world of science.

There is doubt if imaginations can infiltrate into quantitative research. The methods of gaining knowledge if the world must experience technological advancement must be through an orderly means. In fact, Padmanabhan and Gafoor argue that:

In as much as any knowledge is empirical knowledge in one form or another, no speculation can be knowledge. Positivism has not escaped the lot of traditional philosophy, since its own propositions (rejection of speculation, phenomenalism, etc.) turned out to be unverifiable by experience and, consequently, metaphysical (Padmanabhan \& Gafoor, 2011:19).

There is no doubt that speculation cannot be accepted as what one claim to know, this is because the knowledge in quote does not come through one of the five senses in which knowledge can be gained. YacobHaliso noted that:

Only knowledge apprehended by the use of five human senses can be considered to exist as such knowledge can also be experienced by others coming into contact with it, and does not depend on the say-so of any single person (Yacob-Haliso, 2016:8)

Even though, proponents of positivism like Comte did not believe in research that is beclouded with creative imagination, researchers that favour positivism or quantitative research are most often over-taken by 
their emotion in what they do since this is what keeps them going in the research. Pickering (1993:1) best captured this fact, "although Comte never turned his attention to writing fiction, he remained thoroughly preoccupied by his own emotional development, which increasingly dominated his philosophy". To say that creative imagination is useful at the early stage of research, especially when formulating hypotheses might not be out of place. The foregoing is best encapsulated in the writing of Pickering in the course of reviewing Comte's work:

Comte introduced the "art" of "scientific fictions," which he acknowledged derived from the "poetic imagination." Whereas the art of hypothesis related fictions to the solution of a problem, this other art applied them to the problem itself by inventing a series of purely hypothetical cases. One example of the possible use of this new method in biology would be to place "purely fictive organisms," which one hoped to discover later, between already known organisms in order to make the biological series more homogeneous, continuous, and regular (Pickering, 1993:568)

Comte believed that there is an element of fiction in the course of framing hypotheses; the scholar refers to this as the 'art of scientific fiction'. The scholar further holds that, hypothesis which relates to fiction will eventually lead to the solution of the problem after such hypothesis must have been tested. Quantitative research favours testing of hypotheses, while arts based research where poetic imagination came from seldom favour testing hypotheses. In a way, fiction is useful in research, though it should be empirically verified.

One of the goals of every research is to gain knowledge. There is doubt if the purpose of using fiction in research is also to gain knowledge. However, the way this knowledge is being gained differs. Rogers notes that:

It is important in fiction based research that research renderings allow a multiplicity of meanings to emerge. Readers bring their own unique perspectives to fiction. This presence of ambiguity helps readers to reflect on the story as a whole while including their own experiences in relation to the story. As with all quantitative and qualitative research, fiction-based research contains substantive content. The researcher's goal is to share knowledge about a certain topic by educating, raising awareness, or cultivating understanding. It is important that the story is useful and that readers learn something from the text (Rogers, 2014:3).

Fiction based research is an arts based research that is qualitative research inclined, though the instruments of gathering data differ from that of social sciences. Arts based research uses creative imagination as instrument of gathering data, while research in social sciences do not use creative imaginations as instrument of data collection. It is believed that the goal of arts based research is to share knowledge about a particular subject. It is as a result of this that Rogers (2014:4) further posit that, "in qualitative research, no single truth occurs, and truth is dependent on context and individuals' life experiences". However, it will not be fair for Rogers to say there is no single truth in qualitative research, since arts based research that employ creative imagination is just an aspect of qualitative research. Although truth cannot be said to exist in research if it has been overridden by creative imagination, however such research can still be accepted provided the purpose is to share knowledge.

At times what researchers see as facts might be a mere imagination. Thus, iota of imagination might just be what researchers claimed to have observed. The above observation is best captured in the words of Trochim:

The post-positivist recognizes that all observation is fallible and has error and that all theory is revisable. Where the positivist believed that the goal of science was to uncover the truth, the post-positivism believes that the goal of science is to hold steadfastly to the goal of getting it right about reality, even though we can never achieve that goal! (Trochim, 2014:1)

Post-positivist or neo-positivist or non-positivism as the case maybe is referred to as qualitative research. Observation whether is pure science or behavioural science has the tendency of being rejected through new theories. For example, the world was initially believed to be flat and people come to believe it. The assertion remained true until new research proved that the world is 'sphere in shape', but not flat as formerly claimed. The former truth is now as good as a product of 'imagination'. It means that, imagination is also an element of positivist, since positivist once believed that the world is flat, but later claimed on the contrary that the world is sphere. There is no doubt that imagination exist in positivism. On the fact that observation is fallible, Trochim (2006) further observed that, most post-positivists are constructivists who believe that we each construct our view of the world based on our perceptions of it. Because perception and observation is fallible, our constructions must be imperfect. So what is meant by objectivity in a post-positivist world? Qualitative researchers tend to be more objective than positivist because the former accept the fact that observation can be prone to error, while the latter does not believe that observation can be prone to error. What is seen as the facts today can turn to be false through further research; hence truth is not absolute as claimed by positivists. 
Thus, on the submission that observation is fallible, Marsonet (2002) observes that, in mathematics the discovery of non-Euclidean geometry cast doubt upon the Euclidian conception of space. Research in mathematics, which is a pure science and other arts based, researched that observation is fallible. There is no doubt that observation is fallible, the truth remains that there is an absolute truth which must be discovered in whichever means researchers used in carrying out their research. The observation of Marsonet best captured this:

What in fact does "Positivism" mean? According to the French thinker, starting from the beginning up until the 19th Century, our way of thinking is divided into three major phases: the first being the "theological" phase, the second is "metaphysical", and the third is "scientific," or rather, to be more precise, "positivist." The first, the theological phase is characterized by the supremacy of mythology, seeing nature as a living being, manifesting divine attributes. The second phase is dominated by metaphysics; here human beings claim knowledge concerning nature, putting forward theories (at this point, void of any divine characteristics) using abstract thought (Marsonet, 2002).

Positivism came into being for the purpose of providing answers to questions that relates to technological advancement that the scholars who perceived nature as a living being manifesting divine features and scholars who claim knowledge through abstract thought. The first and second approaches to acquiring knowledge that came before positivism were criticized for being normative and full of imagination. Thus, positivism has also been infiltrated with imagination that theologian and philosophers have been accused of.

The claim of objectivity by the positivist is something that is born out of scientific imagination because of the following questions. Why will a positivist choose to carry out a research on, "the attitude of voters in the 2015 General Election and not 2011 General Election? Why will scientific researcher choose to study location ' $A$ ' in Nigeria and not location 'B'? Again, why will positivist researchers choose to administer questionnaire to their subjects and not to interview the subjects? The foregoing is born out of researchers' imagination to discover the truth. The above view is shared by Douglas (2011:517) in "given the starting points of valuing empirical science and a particular set of ideas about what is significant in social life, objective truths are possible as long as one does not confuse the normative and the descriptive as one's scientific work goes forward". There will always be imagination in research, since anything that is not 'facts based' are mere imagination.

In fact, the Christian religion believes so much in creative imagination in making known the mystery of the kingdom of Heaven. This is evidence in the write up of most arts based research, especially in the arts based researched (for example, Department of Religious Studies). Research in this field sees the bible as their research instrument where scholars can draw inspiration from. It should be noted that this bible (scripture) uses many parables and creative imagination to pass knowledge. Parable is not something that is backed up with facts, though it is educative. The reason for using creative imagination from the scripture is because it is a source of secondary data for arts based research. The scripture where Jesus teaches his disciples about the kingdom of God goes thus:

another parable he put forth to them, saying, "the kingdom of heaven is like a man who sowed good seed in his field; but while men slept, his enemy came and sowed tares among the wheat and went his way; but when the grain had sprouted and produced a crop, then the tares also appeared; so the servants of the owner came and said to him, Sir, did we not sow, good seed in your field? How then does it have tares? He said to them, an enemy has done this. The servants said to him, do you want us then to go and gather them up?; but he said, No, lest while you gather up the tares you also uproot the wheat with them; let both grow together until the harvest, and at the time of harvest, I will say to the reapers, first gather together the tares and bind them in bundles to burn them, but gather the wheat into my barn (New King James Version, Mathew, 13:24-30).

There is no doubt that knowledge gained from spiritual source was the fore runner in the phases of knowing what we claim to know. During this time, what we claim to know is link to Supreme Being. Comte (n.d) best captured it in this way, in the 19th Century, philosophy "had to" become positivist since it had traveled along quite a "natural" road, leading it from the mythical to the conceptual abstract process. The only true knowledge available is that which came from the sciences, which from Galileo onwards, had been liberated from philosophical custody (cited in Marsonet, 2002). From the above observation, it can be deduced that how we know what we know does not start from positivism, rather it traveled from mythical approach to normative positivism. To now believe that knowledge can only be gained through positivism (quantitative research) is to say nothing as an academia.

The belief of certain culture is a product of imagination. In the words of Weber (1949:110), "the belief in 
the value of scientific truth is the product of certain cultures and is not a product of man's original nature" (Cited in Douglas, 2011:515). There is no doubt that, there is always the issue of preference in whichever research one wants to embark upon. For instance, when a research believes that it is only quantitative research that will enable one to have valid conclusion, it is itself a product of imagination. Douglas (2011: 515) further holds that, "the very fact that empirical truths, and the social science that produces them, is valued at all is based on a particular cultural value". Whenever there is value, imagination is inevitable. Value is not empiricism so also do imagination.

The belief that knowledge come from science alone is not fair and it is a mere scientific imagination. There is a wise saying that, 'it is only a fool that will say there is no God'. A college professor once believed that 'God is dead' and he even went ahead to tell his students to write, 'God is dead' on an empty white paper, which virtually every student does except one of them that believed otherwise (God is not dead). In the subsequent class, the student who believed that God is not dead asked his professor, 'why he hates God'. The college professor later confessed that God allowed calamity to befall him, hence, 'God is dead' (Sorbo, Harper, White et al (2010). However, Marsonet argues that:

Knowledge comes from science and metaphysical statements are meaningless. This theory was vividly illustrated in the Circle's "Manifesto" where it states: "If someone asserts that there is a God, the primary basis of the world in the unconscious, there is an entelechy which is the leading principle in the living organism, we do not say to him: what you say is false; but we ask him: what do you mean by these statements? Then it appears that there is a sharp boundary between two kinds of statements. To one belong statements as they are made by empirical science; their meaning can be determined by logical analysis or, more precisely through reduction to the simplest statements about the empirically given (Marsonet, 2002: 306 - 307).

To believe that knowledge can only be acquired through science is to say that knowledge has not been gained and that the world has not benefited from the knowledge of religious leaders and philosophers. Simply because something cannot be verified now does not mean that it cannot be verified later. However, Marsonet (2002) contends that, philosophers themselves could do nothing other than analyze the only meaningful discourse, that is the scientific one. Not only were the metaphysical propositions considered as being false, but also meaningless, since they seek to study a world of entities of which nothing can be said. The fact that philosophers' analyses scientific discourse means that imagination has the tendency of infiltrating into scientific research and that science based research is prone to imagination. It also means that scientific research is not free from interpretation of researchers.

It is a mere imagination to argue that majority has the facts. Quantitative and qualitative research methods believe in popular opinion or major respondent to arrive at conclusion, whereas majority of the subject might not always be right at times. In the words of Biereenu-Nnabugwu, (2011:109), "fallacy of argumentum ad populum'; erroneously believes that the truth lies with the majority. Is also refers to as fallacy of band wagon". In the course of gathering quantitative data, researcher can mistakenly administer questionnaire to subjects that won't give true report about needed information that the researcher required. This can make the outcome of the research to be rooted on imagination, rather than facts. This type of imagination can also take place in qualitative research, when questionnaire is administered to subject that gave wrong opinion about social phenomena.

Neo-positivists pointed the way to renewing the link between science, philosophy and metaphysics, and no doubt that the study of the relationship among these disciplines benefited from some of their scathing analyses (Marsonet, 2002). Positivism that promotes quantitative research has been of great benefit to the society at large, however neglecting other methods of gaining knowledge because they are not quantifiable or do not follow some scientific pattern is not being fair. To say that quantitative research has completely solved the problem of humanity will be unfair also. Imagination is something that researchers in behavioural sciences always run away from, however researchers at one point or the other see their research works being clouded with imagination.

\section{Conclusion}

The paper has been able to discuss facts and fiction in behavioural sciences. Positivism and neo-positivism (neopositivism or post-positivism) are two major research paradigms in behavioural science that gave birth to quantitative and qualitative research respectively. It is a fact that research in behavioural sciences study social phenomena, unlike the research in pure sciences. 
Table 1: Positivism and neo-positivism approach to research work

\begin{tabular}{|l|l|l|}
\hline Types of Research & Positivism & Neo-positivism \\
\hline Also known as & Quantitative research & Qualitative research method \\
\hline Mode of gaining knowledge & Observation & Observation \\
\hline Key research instruments & Questionnaire & $\begin{array}{l}\text { Interviews, focus group discussion, } \\
\text { observation and action research }\end{array}$ \\
\hline Nature of research & Facts based research & Facts based research \\
\hline Nature of thought & Empirical & Empirical \\
\hline Imagination & $\begin{array}{l}\text { Arts of scientific fiction, fallacy } \\
\text { of band wagon }\end{array}$ & $\begin{array}{l}\text { creative imagination, fallacy of band } \\
\text { wagon }\end{array}$ \\
\hline Method of analysis & Descriptive statistical analysis, & Content analysis and documentary study \\
\hline Goal & $\begin{array}{l}\text { To test \& build theory, } \\
\text { prediction, generalisation, to } \\
\text { gain knowledge }\end{array}$ & $\begin{array}{l}\text { To test \& build theory, prediction, } \\
\text { generalisation, to gain knowledge. }\end{array}$ \\
\hline
\end{tabular}

\section{Source: Author}

Qualitative and quantitative research uses observation as the mode of gaining knowledge (use of our five senses); hence the two paradigms believe that anything that cannot be observed lacks validity. Hence, quantitative and qualitative research are facts based researched. In behavioural sciences, quantitative research uses questionnaire to gather data, though action research is also consulted in the course of such research. On the other hand, qualitative research review action research and or interview; focus group discussion and participant observation as the case may be, to gather data. Not only that, quantitative research uses descriptive statistical analysis in its analysis, while qualitative research uses 'content analysis' and other methods in analyzing its findings. Quantitative and qualitative research aimed at the same goal, which is to test and build theory, to predict, generalisation, and to gain knowledge.

Even though quantitative and qualitative researches are facts based research, they end up being infiltrated with imagination they initially try as much as possible to avoid. For instance, both research undertakings often than not fall victim of 'fallacy of band wagon', a situation where majority of the subjects (subject that questionnaire were administered to or subject that interview were administered to) give false observation about social phenomenon they have observed.

\section{References}

Alessandrini, M (n.d). Non-positivist approaches to research in the third sector: Empowered Policy-making. Retrieved from https://www.istr.org. On August 6, 2018.

Asika, N (2012). Research methodology in the behavioural sciences (Reprint). Lagos: Learn Africa PLC.

Azom, S. N (2018). Measurement in political science research. In Nwanolue, B.O., Ezeibe, C.C., Aniche, E.T and Iwuoha, V.C (Eds), Political inquiry and research methodology: Logic, designs, processes, methods and approaches. Enugu: Tarakletos Immunis Drive.

Biereenu-Nnabugwu, M (2006). Methodology of political inquiry: issues and techniques of research methods in political. Enugu: Quintagon Publishers.

Biereenu-Nnabugwu, M (2011). Fundamentals of political inquiry. Enugu: Quintagon Publishers.

Bodner, J (2018). What's the difference between empirical and normative? Retrieved from https://www.quora.com. On August 19, 2018.

Buddharaksa, W (2010). Positivism, anti-positivism and neo-gramscianism. RCAPS Working Paper No. 10-4, December 2010, Ritsumeikan Center for Asia Pacific Studies (RCAPS), Ritsumeikan Asia Pacific University. Retrieved from http://www.apu.ac.jp/rcaps/. On August 25, 2018.

Cambridge University Press (2018).Cambridge dictionary: fiction. Retrieved from https://dictionary.cambridge.org/dictionary/english/fiction. On August $1^{\text {st }}, 2018$.

Douglas, H (2011). Facts, values and objectivity. In Jarvie, I.C and Zamora-Bonilla, J (Eds.), The Philosophy of social science. India: Sage Publications.

Fink, A.S (2000). Role of fiction in quantitative and qualitative research: A potential barrier to archiving qualitative dada. Vol. 1, No. 3, December 2000. Retrieved from www.qualitative-research.net. On August 16, 2018.

Hoover Public Library (2018). What is the difference between fiction and nonfiction. Retrieved from www.hooverlibrary.org/faq/fiction_vs_nonfiction. On August 6, 2018.

Igwe, O. (2007). Politics and globe dictionary (new edition). Enugu: Keny \& Brother Publisher.

Marsonet, M. (2002). Positivism. Retrieved from www.inters.org/positivism. On August 4, 2018.

Mbacha, I.O. (2016). Methods of data analysis/content analysis in social science research. In Aloysius-Michael, Okolie and Godwin, Agene Oga (Eds.), Research methodology in social science analysis. Enugu: Nigeria 
Political Science Association

Ndubuisi, N. E and Chukwuma, N.C (2016). Methods of data collection. In Aloysius-Michael, Okolie and Godwin, Agene Oga (Eds.), Research methodology in social science analysis. Enugu: Nigeria Political Science Association

Obiora, C and Udalla, E (2018). Method of political Inquiry and research paradigms. In Nwanolue, B.O., Ezeibe, C.C., Aniche, E.T and Iwuoha, V.C (Eds), Political inquiry and research methodology: Logic, designs, processes, methods and approaches. Enugu: Tarakletos Immunis Drive.

Olalekan, B. (2015). Who is Orunmila. Retrieved from https://ooduarere.com. On August 18, 2018.

Padmanabhan, N. and Gafoor, P.A. (2011). Methodology of History. India: School of Distance Education, University of Calicut.

Patton, M. Q and Cochran, M (2002). A guide to using qualitative research methodology.

Peter, A. M (2018), Qualitative political inquiry and its foundations. In Nwanolue, B.O., Ezeibe, C.C., Aniche, E.T and Iwuoha, V.C (Eds), Political inquiry and research methodology: Logic, designs, processes, methods and approaches. Enugu: Tarakletos Immunis Drive.

Pickering, M (1993). Auguste Comte: An Intellectual Biography, Volume I. New York: Cambridge University Press

Reihlen, M (2013). Which program is the best for analyzing interviews with qualitative content analysis. Retrieved from https://www.researchgate.net.

Reimer, B. (1996), Qualitative Research and the Post-Positivist Mind. Bulletin of the Council for Research in Music Education, No. 130, Qualitative Methodologies in Music Education Research Conference II (Fall, 1996), pp. 123-126.

Remenyi, D. (2014). Phenomenological: the non-positivist approach. Retrieved from www.phd-researchmethodology.blogspot.com. On August 9, 2018.

Rogers, R. H. (2014). Fiction strengthens research: A Review of Patricia Leavy's Fiction as Research Practice; Short Stories, Novellas, and Novels. The qualitative report, Vol.19, No. 46, pp.1-5

Trochim, W. M. K (2006). Positivism and Post Positivism. Retrieved from www.socialresearchmethods.net/kb/positivism.php. On August 04, 2018.

Yacob-Haliso, O. (2016). Introduction to research. In Aloysius-Michael, Okolie and Godwin, Agene Oga (Eds.), Research methodology in social science analysis. Enugu: Nigeria Political Science Association 